\title{
ASALIBU ISTIDLAL AN NUHAT FI KITAB SYARAH ALFIYAH IBNU 'AQIL
}

\author{
Abdullah Zainur Rauf, Nur Qomari
}

\author{
zainur@bsa.uin-malang.ac.id, qomari@uin-malang.ac.id \\ Universitas Maulana Malik Ibrahim Malang, Jawa Timur, Indonesia \\ Malang, Jawa Timur, Indonesia
}

\begin{abstract}
Nahwu is the key to understanding Arabic texts. Nahwu is growing rapidly so that many nahwu experts write about nahwu theories. And among the experts, there are different views related to the rules of nahwu. This research aims to know the methods of thinking of grammarians in the book Sharh Alfiyah Ibnu 'Aqil. This research uses the qualitative approach to find out the differences between grammarians in controlling grammatical rulings. This research reveals five chapters in which scholars differ, including 1) presenting the subject over the subjunctive 2) abstracting the verb from a sign indicating the duality or plural 3 ) proving the $t$ in the verb and its subject is an authentic feminine and with the separation of only 4) presenting the object on the subject 5) the return of the pronoun from the advanced subject is the delayed subject.
\end{abstract}

Keywords: Istidlal, Nuhat, Nahwu Arabi

$$
\begin{aligned}
& \text { الغزالي في مقاله عن أهمية تعلم اللغة العربية و خاصة النحو } \\
& \text { والصرف "إن اللغة العربية وعلم النحو عبارة عن وسيلة لمعرفة } \\
& \text { معاني القرآن والأحاديث النبوية، رغم من أفما (اللغة العربية }
\end{aligned}
$$

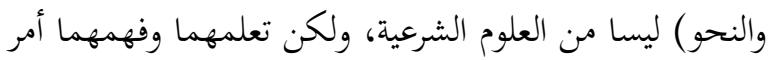

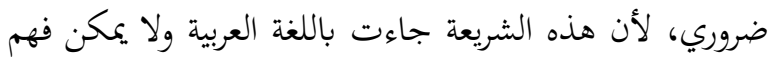

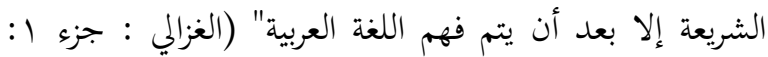

$$
\begin{aligned}
& \text {. (TV } \\
& \text { إن الكتب التي تتناول النحو كثيرة ومتنوعة، ولكل منها }
\end{aligned}
$$

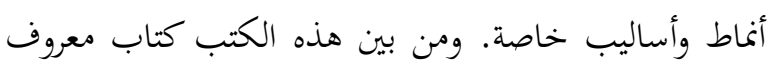

$$
\begin{aligned}
& \text { ومشهور عند طلاب المعاهد الإسلامية بإندونيسيا وهو كتاب بل }
\end{aligned}
$$

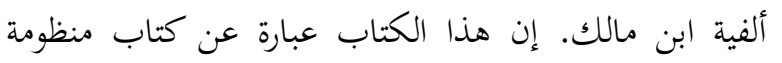

$$
\begin{aligned}
& \text { تتكون من ألف بيت، ويستخدم بحر روجاز، ويتناول هذا }
\end{aligned}
$$

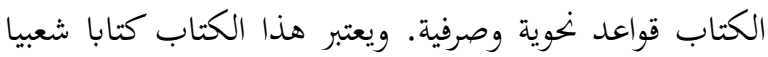

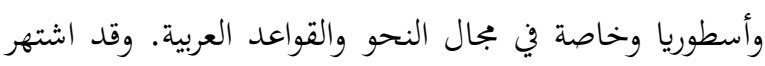

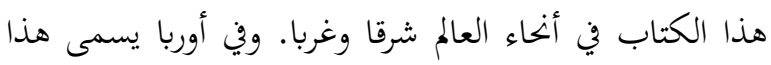

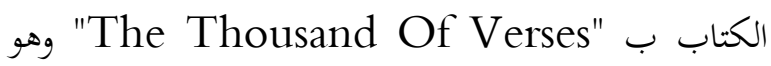

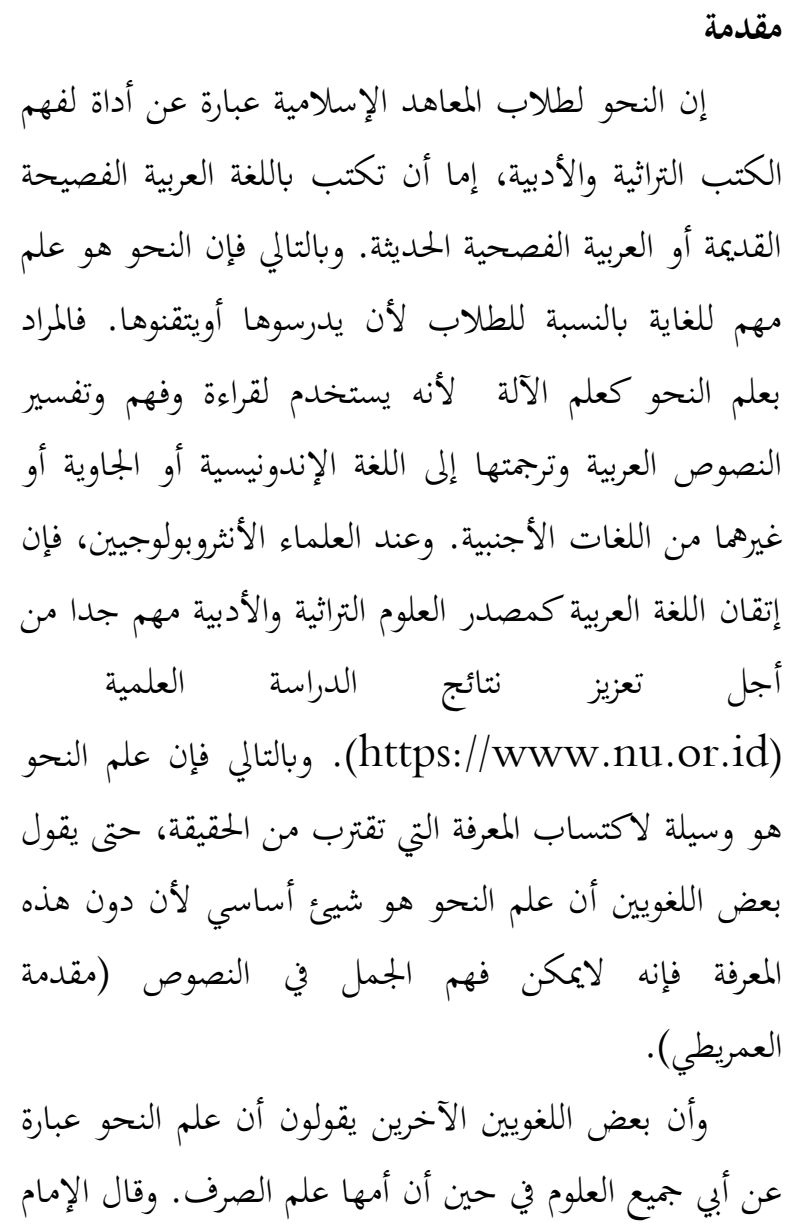


(ه) VT9) كبيرا في مصر. وكانت مؤلفاته كثيرة جدا وأشهرها شرح ألفية ابن عقيل. وفي الحقيقة أن هذا الكتاب بسيط وسهل تعلمه للمبتدئين. ويستطيع ابن عقيل شرح أبيات ألفية بطريقة منهجية حتى يستطيع القارئ فهم مايريد به ابن مالك. وقد انتشر هذا الكتاب في المعاهد الإسلامية بإندونيسيا وماليزيا وتايلاند وكثير من الطلبة في هذه المعاهد يقرؤوها ويفهموها .(http://abusyahmin.blogspot.com) وإن مؤلف هذا الكتاب لايشرح ولايبين أبيات كتاب ألفية فحسب، وإنما يشرح أيضا اختلاف وجهات النظر بين علماء النحو في باب التنازع وهو إذا يوجد عاملان فالمعمول واحد مثل الجملة التالية : قام وقعد أخواك، ومن هذا المثال إذا تعارض العاملان فأين العامل الذي يجب أن قدم من بعضهما بعضا هل هو لفظ قام أم لفظ قعد. وفي هذه المسألة كان يشرح ابن عقيل شرحا واضحا من حجة كل من هذين العاملين مع الدليل المنطقي. فالرأي الأول يقول إن العامل في الجملة السابقة هو لفظ قعد لأنه أقرب مكانا من المعمول (لفظ أخواك)، وأما الرأي الثاني يقول أن العامل هو لفظ قام لأنه أقدم من لفظ قعل في ترتيب الكلمات.

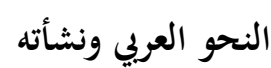

إن النحو علم يدرس تغيير أواخر الكلم إما أن يكون هذا التغيير إعرابا أو أن يكون بناء، وبهذا العلم يعرف أحوال حركات أواخر الكلمات والنظام النحوي للجملة، وترتيب الجملة حيث تكون الكلمة في تلك الجملة تؤدي وظيفة معينة ثم إذا اختل ترتيب الكلمات اختل المعنى المراد (ابن السراح، 1991 19 صفحة 11 اب ). وضع النحو لغرض فصاحة الكام حتى يفهمه السامع فهما صحيحا، وين وضع النحو العربي أسباب وبواعث مختلفة منها بواعث دينية وغير دينية، وأما الأسباب الدينية فتعود إلى حرص العلماء القوي على أداء نصوص القرآن الكريم أداء سليما فصيحا (شوقي ضيف،

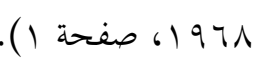

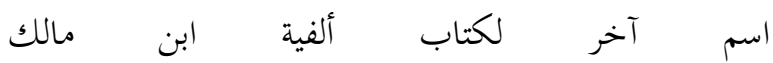
(http://hisabpati.blogspot.com) و سمي هذا الكتاب ألفية لأنه يهتوى على ألف بيت، وكما ذكره العديد من اللغويين أنه ناقش كل مشاكل النحو والصرف، بدءا من مشكلة الكلام، وأنواع الجمل، وأنواع الكلمات، والإعراب وأنواعه، حتى يشتمل البيان على موضع الكلمات في الجملة وغيرها. وقد قدم بعض علماء النحو شرحا لهذا الكتاب (ألفية ابن مالك) مستهدفين إلى توضيح معانيها حتى يسهل فهمه. ومن العلماء الذين قدموا شرحا لهذا الكتاب الشيخ محمد بدر الدين سنة 71 T من الهجرة. وفي هذا الشرح قدمه بعض الانتقادات إلى أفكار نحوية أدلاها والده. ومن أنواع الانتقادات التي قدمها الشيخ محمد بدر الدين مبحث في المفعول المطلق، والتنازع، والصفة المتشابهة. وتعتبر هذه الانتقادات نادرة جدا لشجاعة الولد في نقد تأليفات أبيه. واعتمادا على ذلك، ثم ألف محمد بدر الدين أبات ألفية مقابلة لتأليف أبيه وأخذ الشواهد من القرآن الكريم. ومن هنا، لقد بدأ أن ما ألفه محمد بدر الدين أصبح منطقيا، ولكن معظم العلماء يعرفون بأن النصوص القرآنية (ليس كلها) جازت لها أن تتبع النظريات النحوية المعتمدة عند النحاة. وهذا الشيخ الذي كان في شبابته يعيش في بعلبك أصبح عالما في النحو ولديه وجهات النظر المنطقية لهذا العلم، مع ذلك فإنه يميل إلى النظريات النحوية الشاذة قليلة الاستخدام. ونظرا إلى هذه الظاهرة، لقد ظهر النحاة الجدد مثل ابن هشام وابن عقيل الأثموني الذين يحاولان تعديل أفكار ابن مالك. ومع ذلك، فإن كتاب شرح ألفية لمحمد بدر الدين يلفت أنظار العلماء الكبار بالدليل أن كتابه وضع له حاشية، مثل تأليف ابن جماعة (19 (19 هجرية)، والعيني (100 هجرية)، وزكريا الأنصاري (0ب9 هجرية)، والسيوطي (11ا9 هجرية)، وابن قاسم العبادي (ع99 هجرية)، والقاضي تقي الدين ابن القادر

$$
\text { التميمي (0. . . 1 هجرية). }
$$

وما عدا الكتاب الذي تم ذكره سابقا، فهناك كتاب شرح ألفية الذي ألفه ابن عقيل المسمى بشرح ألفية ابن عقيل 


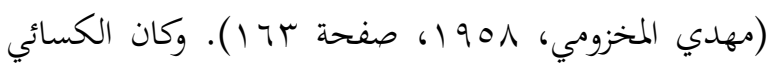

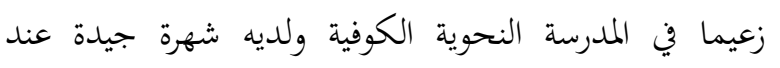

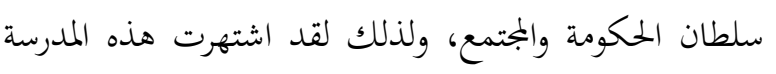

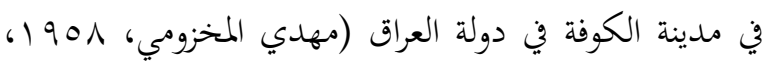

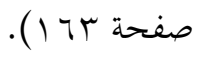

ورغم من أن المدرسة الكوفية تتأثر بالمدرسة البصرية إلا أن الكوفيين مخالفون البصريين في أكثر القواعد الأساسية

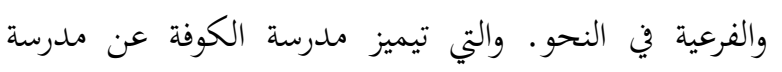

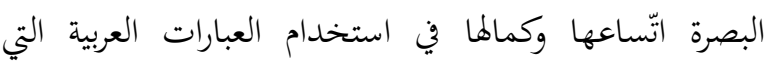

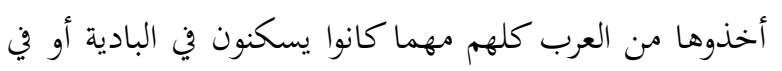

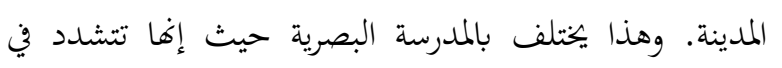

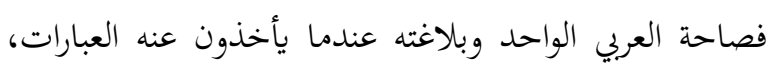

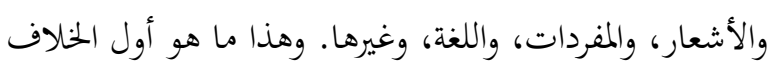

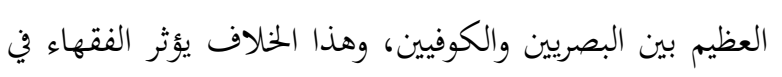

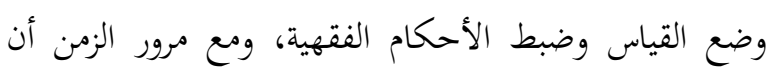

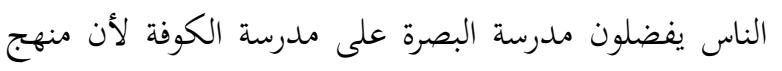

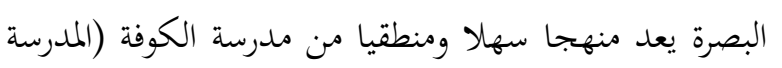
الكوفية، Www.alukah.net)

$$
\text { ج- مدرسة بغداد }
$$

وكان سبب من أسباب تاسيس مدرسة بغداد رؤية بعض بغلد

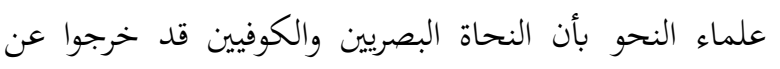

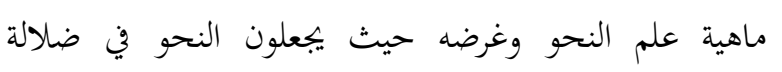
لايمكن إنقاذها، ولذلك شرع علماء النحو في البغداد أن يأخذ موقفا وسطيا بين مذهب البصرة والكوفة. ثم تأسست مدرسة البهاء بغداد وأخذ الخلفاء يشجعون العلماء ويدعوفم لتربية أولادهم.

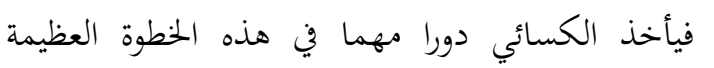
حيث يعلم أولاد خليفة هارون الرشيد، وكان له تلميذ اسمه

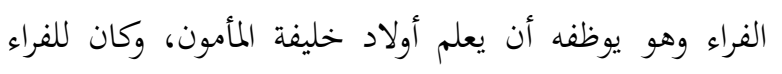

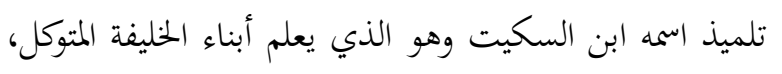

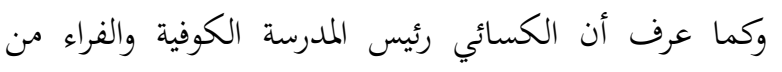

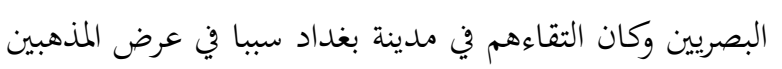

وبهذا الحرص والإرادة القوية من قبل العلماء نشأ علم

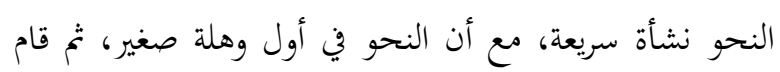

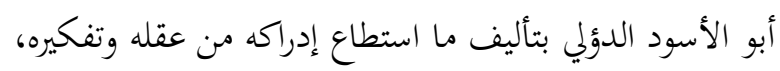
واستمر جهده وعمل بخير ما عنده من وضع النحو العربي. وكان العلماء لم يكونوا على يقين فيما فعله ووضعه أبو الأسود

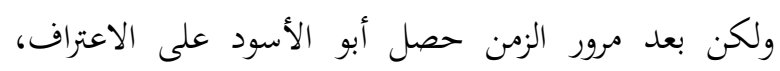

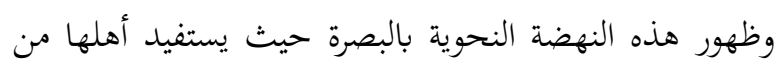

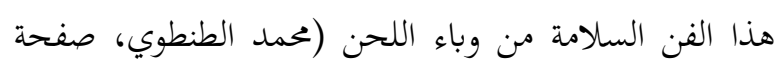

$$
\text { أــ مدرسة البصرة ومدارسهم النحوية }
$$

ولد علم النحو في البصرة، وأول من سلك في علم اللغة

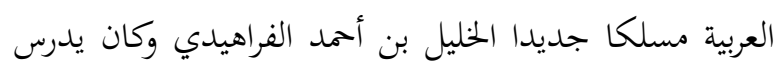

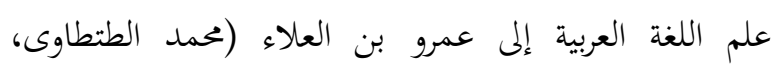

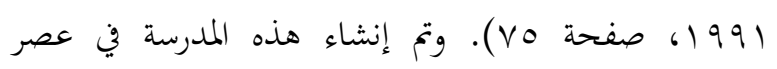
حكومة العباسيين، وتعد من إحدى المدارس النحوية التي تم

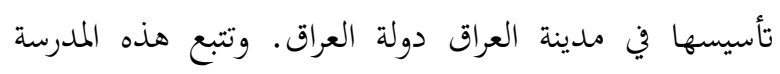
منهجا خاصا في البحث النحوي وهو إن البصريين لديهم حرية

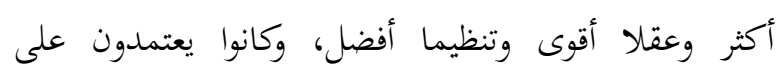
الشواهد الموثوقة عندما يستنبطون الأحكام النحوية، وأصبح مشهورا ما قاله السيوطي بأن البصريين أصح قياسا لأفم

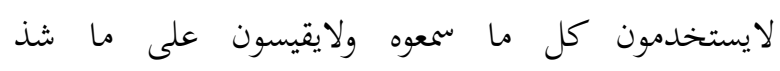

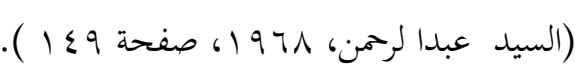
ب- مدرسة الكوفة تأخر نشأة مدرسة الكوفة عن البصرة حيث إفم أخذوا

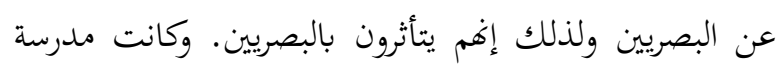
الكوفة تنشأ بعد مئة عام من تأسيس مدرسة البصرة. وكانت مصنفات الكوفيين لم تكن متوفرة كثيرة حتى يكون المعنيون بعلم النحو ناقصين عن معلومات نمو مدرسة الكوفة (بروكلمان

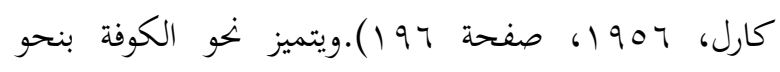
البصرة حيث إن نحو الكوفة يدرس النحو الاصطلاحي

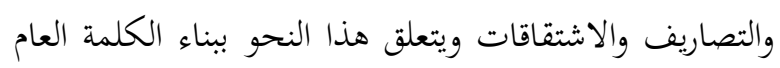


جاور غير العرب لفساد ألسنتهم (محمد غالب وراق، . (199)

\section{منهجية البحث}

استخدم هذا البحث تصميم تحليل المختوى في تحليل البحس

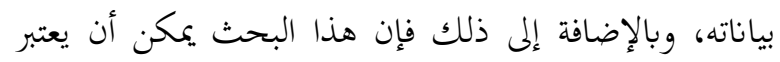
بحثا كيفيا، لأن في هذا البحث خصائص كيفية منها مشاركة الباحث في هذا البحث كأداة رئيسية في جمع البيانات

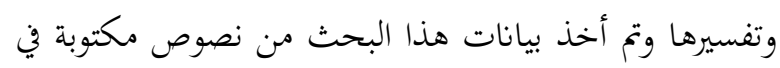

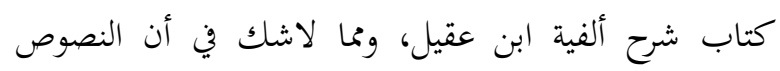
تحتوى على كثير من اختلاف الآراء ووجهة النظر بين علماء النحو في وضع الأحكام النحوية. وجمع البيانات تم بقراءة

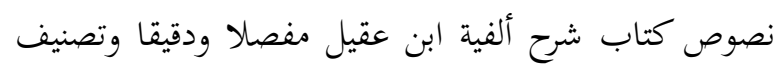

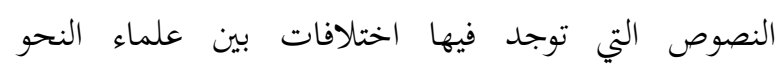

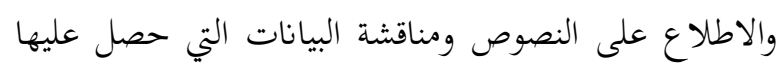
الباحث مع المشايخ وخاصة فيما يتعلق بظاهرة اختلاف علماء

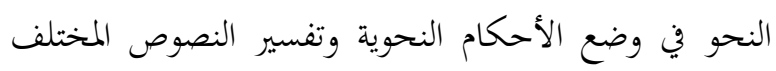
فيها وشرحها دقيقا. وبعد أن تم جمع البيانات، يقوم الباحثان

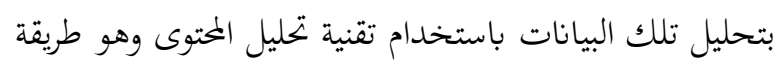
لدراسة وتحليل التواصل منطقيا وموضوعيا وكميا للرسالة

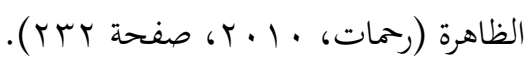

\section{نتائج البحث}

$$
\text { الأول: تقديم الفاعل على الرافع }
$$

قال ابن عقيل في كتابه شرح ابن عقيل أن الن الفاعل

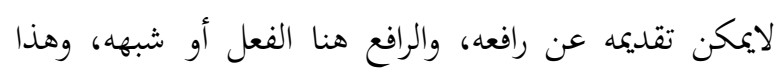

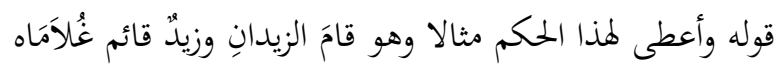

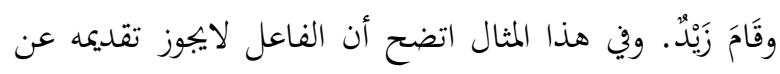

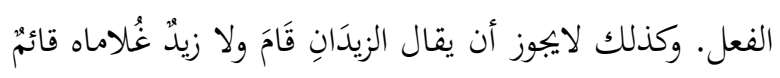

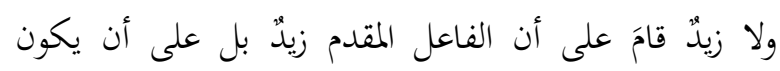

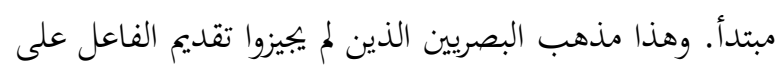

ونقدهما والانتخاب منهما ( أمين احمد، سو ال، صفحة

\section{أصول النحو والاستدلال بما}

أ- القرآن: إن القرآن أصل من الصول الصول وضع القواعد النحوية، فلمراد بالقرآن هنا كل ورد وقرئ سواء كان إن العران

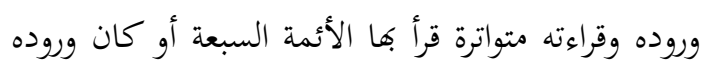
آحادا حيث يروي عنه بعضهم ولم يكن متواترا أو كانت قراءته شاذة وهي القراءة التي جاءت عن غيت عير الأئمة

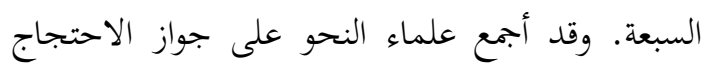

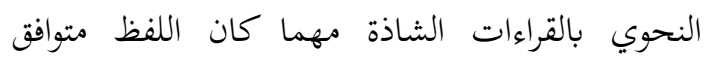
ومتقارب ولو كان أحد اللفظين عربي والآخر غيره، وأهم

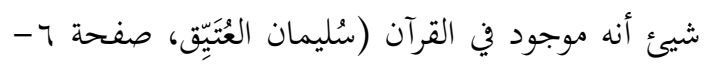
ب- الحديث الشريف: والمراد بالحديث الشريف هو حديث

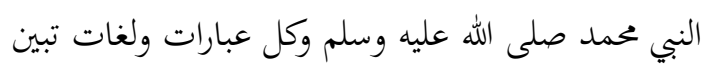

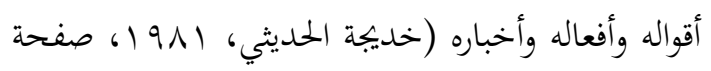
• r).

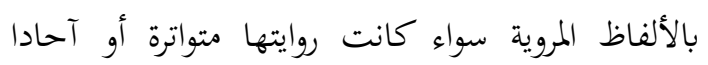

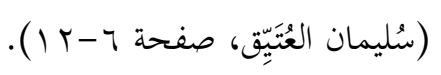

ج- كلام العرب: والمراد بكلام العرب هو كلام فصيح مأخوذ

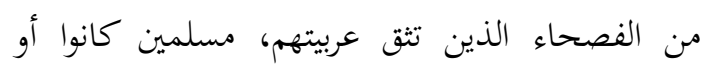
كافرين. ومن كلام العرب كلام قبيلة قريش وقيس وتميم وأسد وهذيل وبعض كنانة وبعض الطائيين (سُليمان

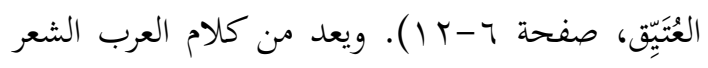

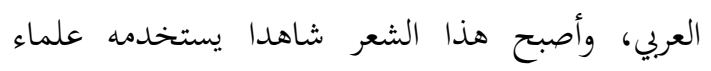
النحو في وضع الأحكام النحوية وتقعيد قواعد نهوية،

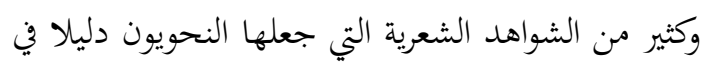
تقعيد القواعد النحوية وكانوا يتوارثون هذه الشواهد جيلا

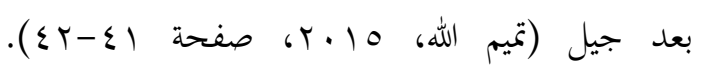
ولاشك في أن استنباطات القواعد العربية معظمها

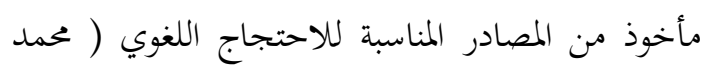

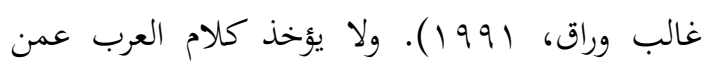


سبب رئيسي في تقعيد النحو لأنه أصبح مرجعا أساسيا في

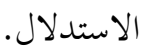

الثاني: عدم تجريد الفعل من علامة تدل على التثنية أو

الجمع

ويقال في كتاب شرح ابن عقيل "إذا أسند الفعل إلى

ظاهر مثنَّى أو مجموع وجب تبجرياه من علامة تدل على ابلى الثنية

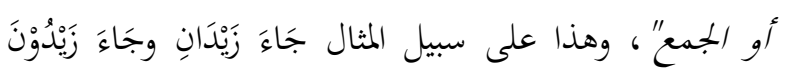

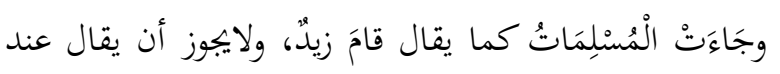

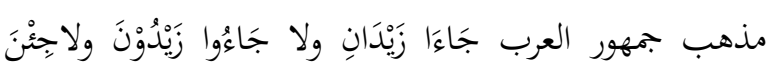

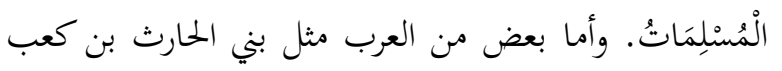

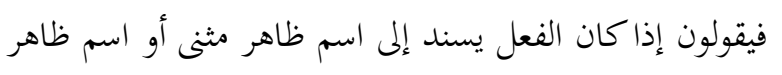

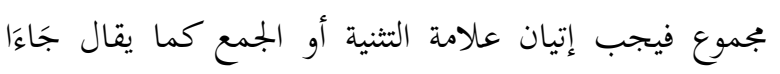

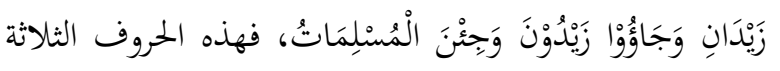

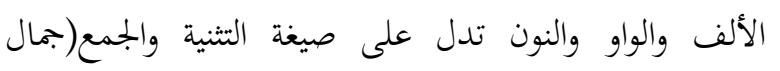

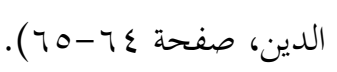

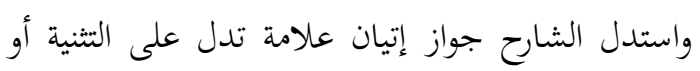
الجمع إذا أسند الفعل إلى اسم ظاهر بقوله: "تَولَّلى قتِّاَل

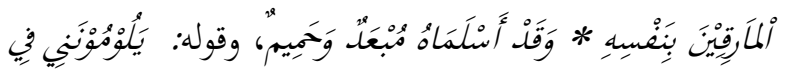

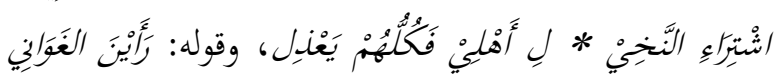

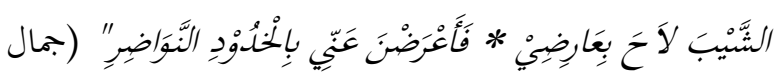

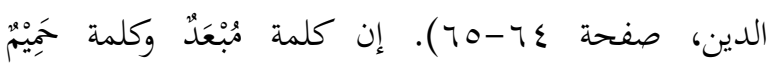

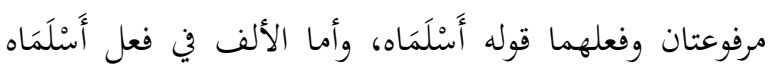

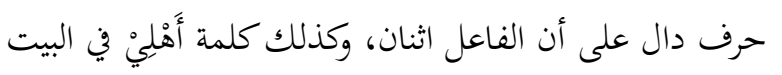

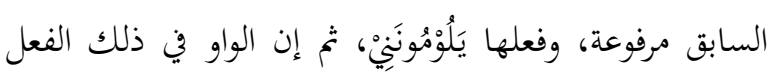

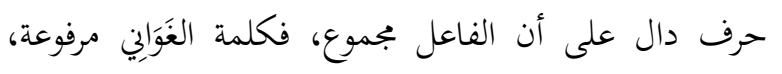

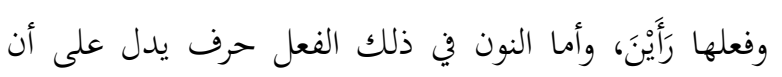

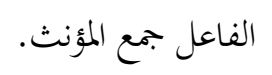

وهناك حديث نبوي استدل الشارح به على إجازة علامة لموني

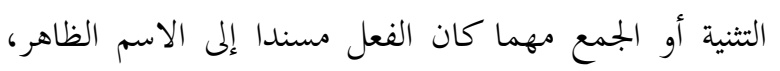

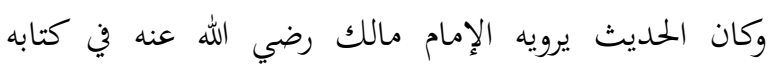

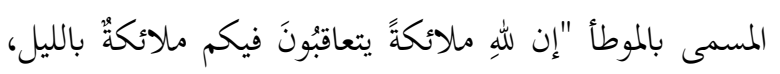

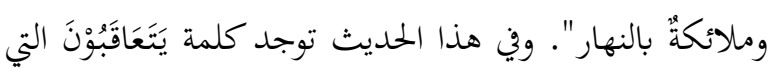

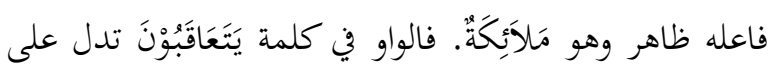

الفعل أو شبهه، وأما الكوفيون فأجازوا التقديم (جمال الدين،

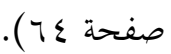

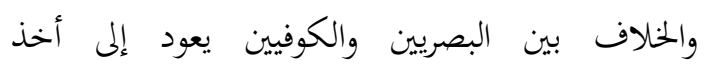
الاستدلال بالأصول النحوية حيث يكون الكوفيون مستدلين على جواز تقديم الفاعل على الفعل بورود الدليل عن كلام

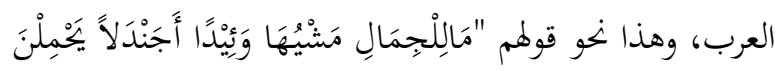

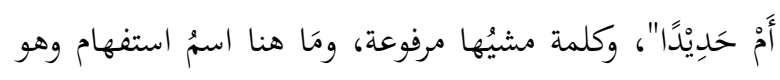

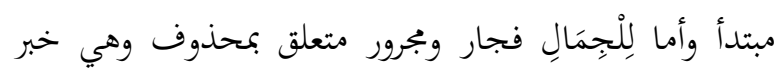

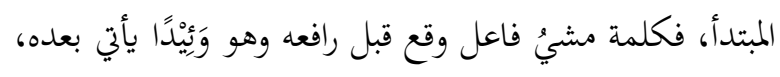
ومَشْيُ كذلك مضاف وأما الضمير الذي يعود إلى الجمال

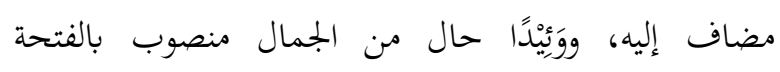

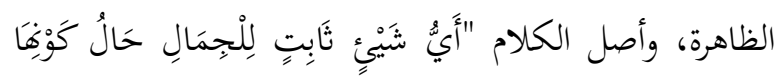
وَِيَيْدًا مَنْنْيُها". وأما البصريون فاستدلوا على أن تقديم الفاعل على فعله

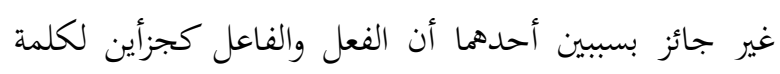

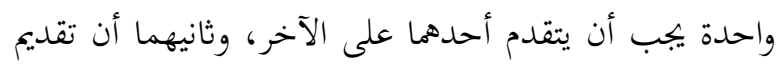

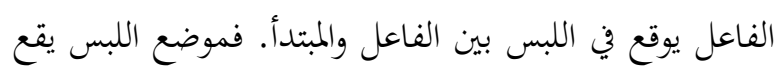

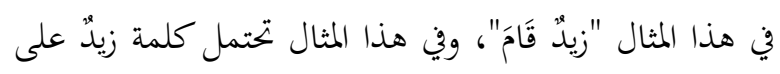

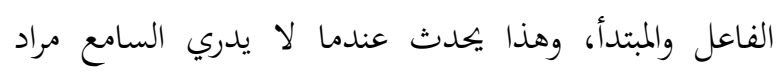

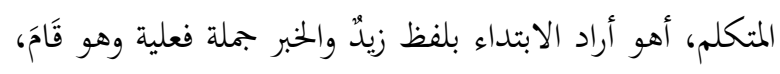

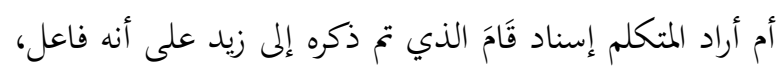
وأما قام حينئذ فخال عن الضمير. وأن هذه المسئلة أمر معقول حيث فيث الفير يرى البصريون أن

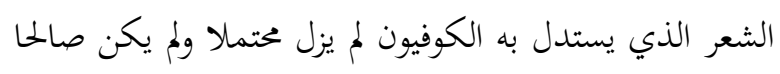

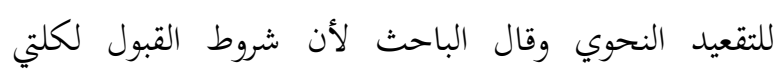

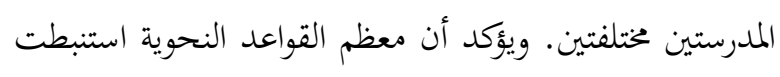

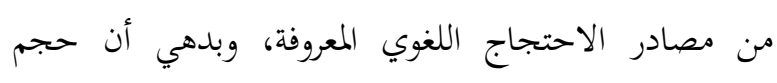
القواعد التي عول عليها على أساليب الشعر أكثر من غيرها،

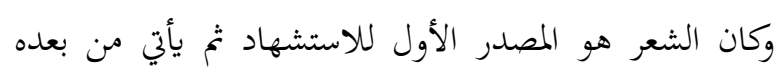

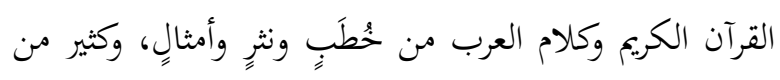
كتب النحو يؤكد هذه الحقيقة (محمد غالب وراق، 1999 1) ). ومن هنا يرى الباحث أن معيار القبول بين النحاة مختلف وهو النداف 
وقد تبين بأن علماء النحو في هذه المسألة مختلفون،

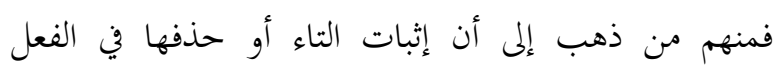

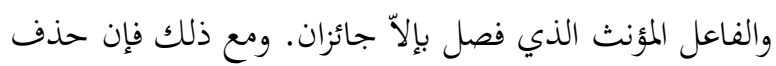

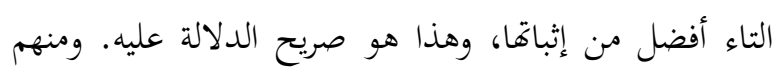

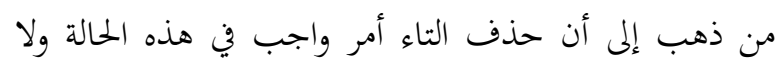

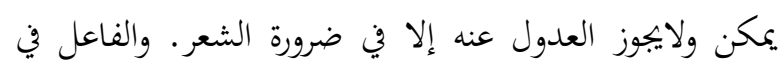

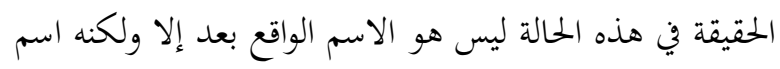

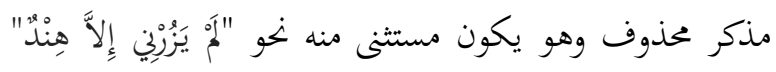

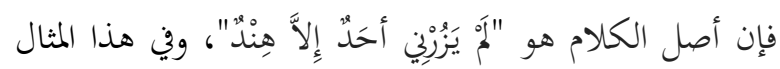

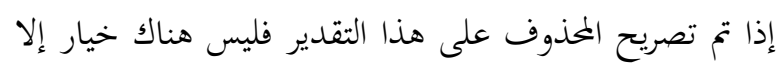
حذف التاء، لأن الفاعل مذكر . الرابع: تقديم المفعول على الفاعل يجب الفاعل عند ابن عقيل أن يكون مقدما على لمعلى المعلى

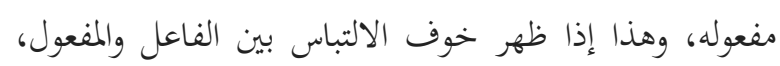

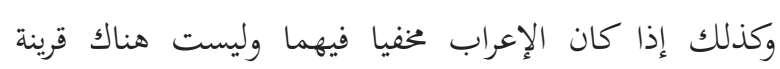

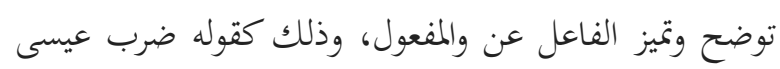

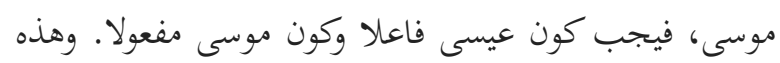

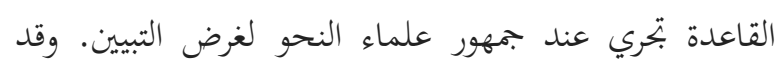

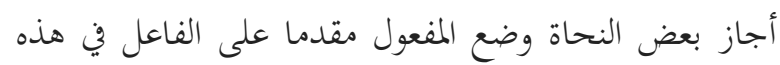

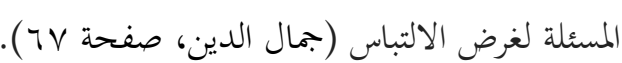

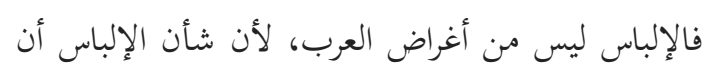

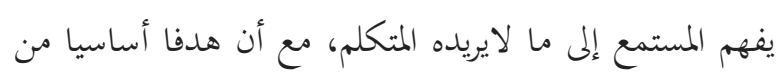
أهداف اللغة إفهام الآخرين. ولنلك يجب إئب أن يفرق تفريقا

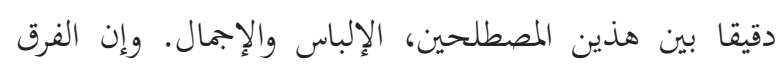

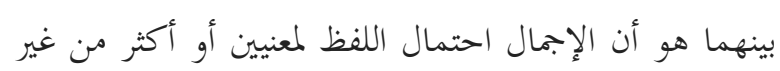
أن يسبق أحد المعنيين إلى ذهن المستمع، ومثال ذلك لو لو قلت التمال

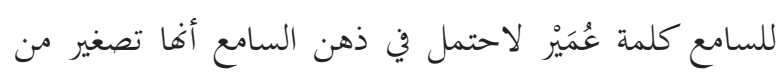
كلمة عمر أو عمرو، دون أن يكون أحدهما أسبق إلى ذهنه إهن.

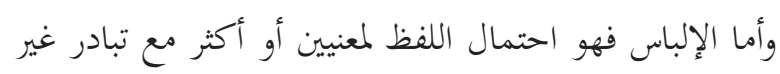

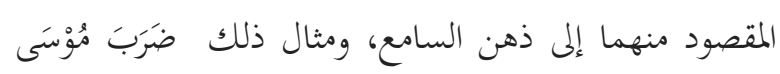

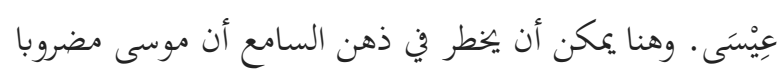

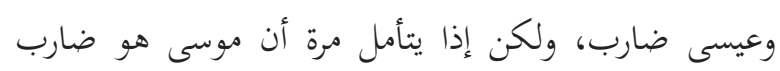
لأن الفاعل أن يكون في الأول.
أهما فاعل. ومثل هذه العبارة قليل ولكن قد يعبر عنه علماء

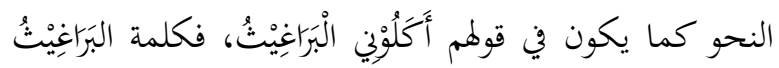

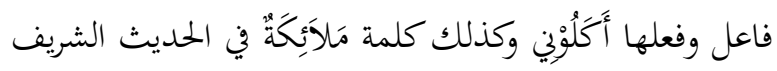
السابق فاعل وفعلها يتعاقبون (جمال الدين، صفححة ـ ؟-

ومن هنا اتضح بأن هناك قوم يستدل بالحديث

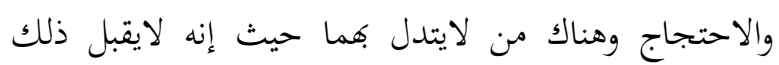

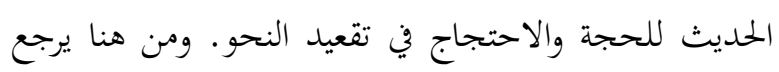

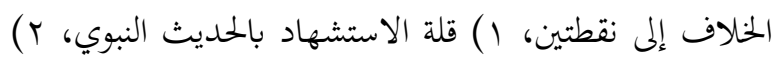

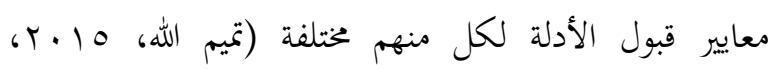
صفحة (YN-TV). الثالث: إثبات التاء أو حذفها في الفعل وفاعله مؤنث حقيقي و مع فصل بإلا

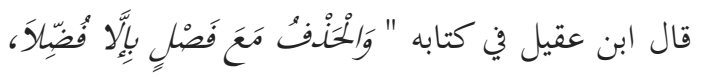

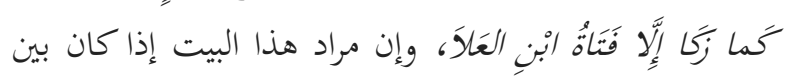

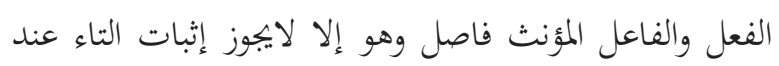

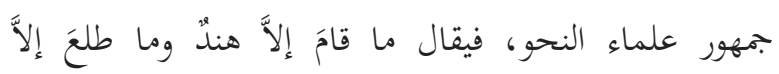

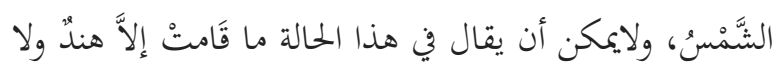

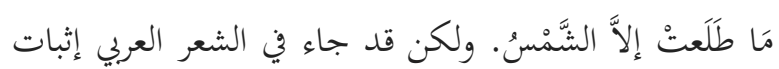
تاء التأنيث ولو كان بين الفعل والفاعل المؤنث فصل بـ بل إلاء

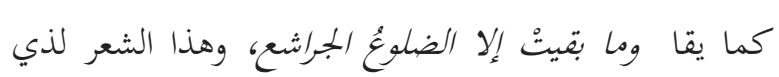

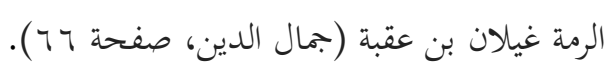
وبالإضافة إلى دليل الشعر عن جواز إثبات التاء، فإن إن إنان مذهب ابن مالك الذي أجاز الإثبات، له أصل في لسان

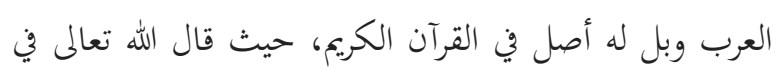

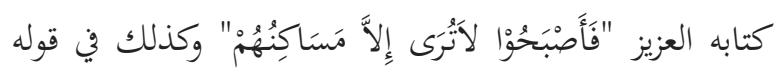

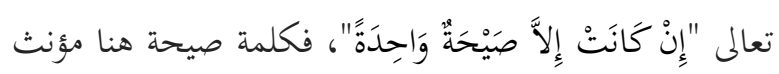

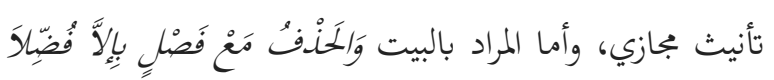

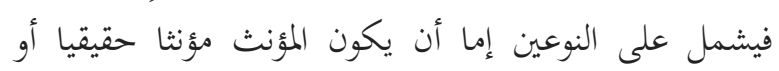
بجازيا تأنيثا مؤنثا http://islamilimleri.com/Kulliyat/Lugat) 
نداه ذا الندى في ذرى المجلد، وقوله: ولو أن مجدا أخلد الدهر

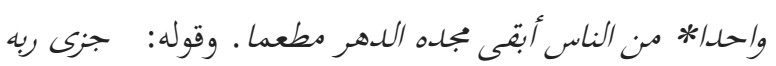
عني علدي بن حاتم * جزاء الكلاب العاويات وقد فعل، وقوله: جزى بنوه أبا الغيلان عن كبر * * وحسن فعل كماء بيزي سنمار.

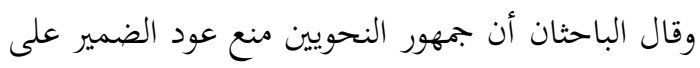

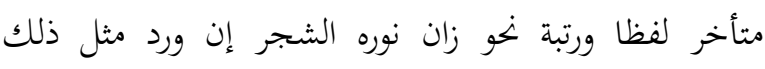

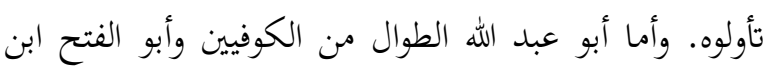
جنى وتابعهما المصنف فأجاز ذلك مثل ما ورد في أبيات

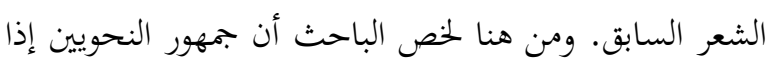
منع الحكم حيث لا يوافق بأصولمم في التقعيد النحوي يقومون

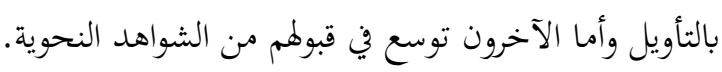

\section{الخلاصة}

والمباحث التي حصل عليها الباحثان من خلاف النحاة هي تقديم الفاعل على الرافع، وبتريد الفعل من علامة تدل

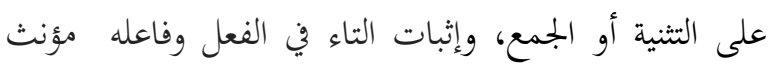

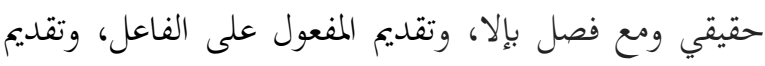
المفعول المشتمل على ضمير يرجع إلى الفاعل المتأخر . وأما أراء

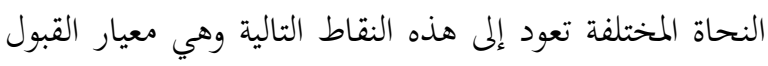

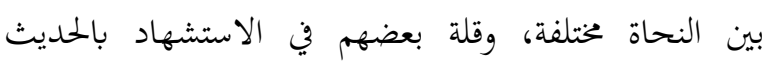
النبوي، واختلافهم في التفسير الدقيق عن المراد باعتماد

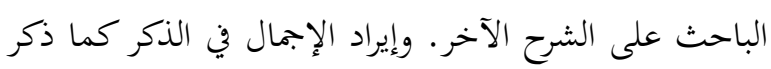
في تقديم المفعول على الفاعل، والانتقال إلى التأويل إذا لم

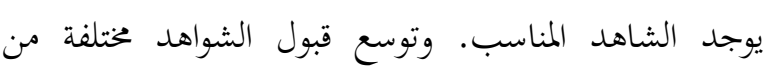

بينهم.

المراجع

\section{الخامس: تقديم المفعول المثتمل على ضمير يرجع إلى} الفاعل المتأخر إن المفعول يمكن أن يتقدم على الفاعل إذا اشتمل على

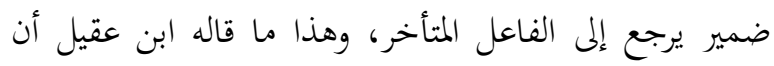

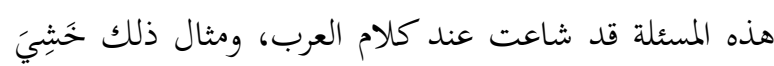

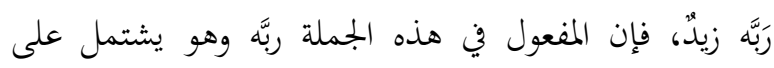

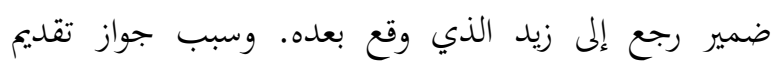

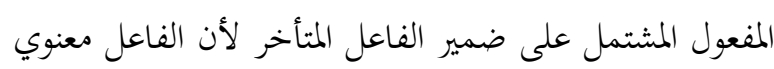

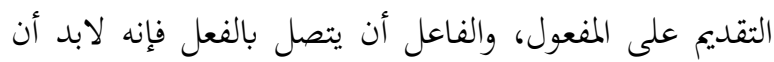
يتقدم رتبة وإن تأخر لفظا.

ويقع الخلاف بين العلماء النحويين إذا كان المفعول

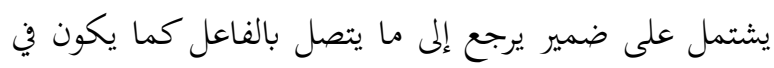

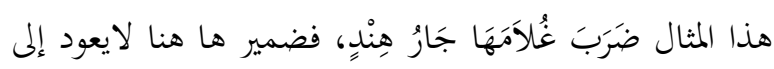

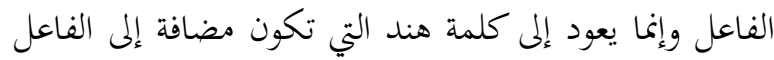

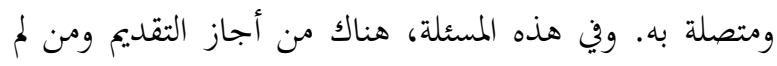

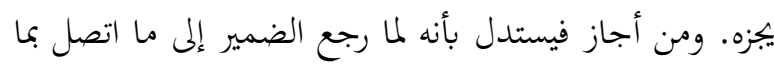
يجب عليه التقديم رتبة فهو كما يعود على ما رتبته التقديم لأن كل المتصل بالمتقدم متقدم. وإذا عاد ضمير الفاعل المتقدم على المفعول المتأخر نحو قوله زان نوره الشجر فلاييجوز عود

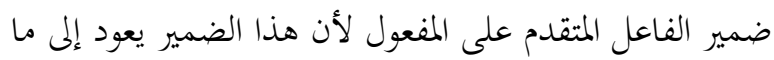

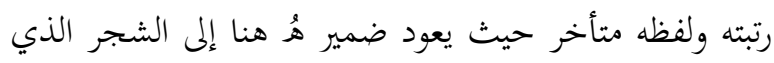
يكون مفعولا به، فالمفعول به رتبته متأخر وكذلك لفظه.

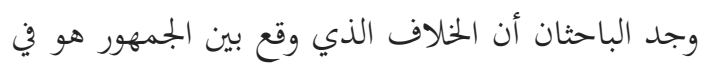
التأويل لأن ابن عقيل أورد بعض الشواهد الشعرية حيث قال الشال

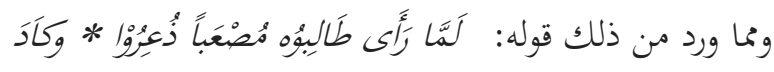

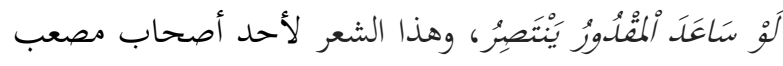

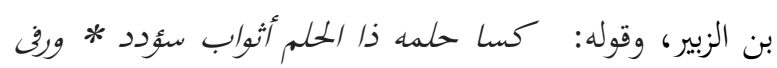

أ- المراجع العربية مجد الدين أبو طاهر محمد بن يعقوب الفيروز آبادى، ه . . T م، القاموس المحيط، بيروت - لبنان مؤسسة الرسالة للطباعة والنشر والتوزيع.

حضر مويى محمد حمود، +. . T، النحو والنحاة، المدارس والخصائص. 
محمد بن السري البغدادي لابن السراح، • 191 1، الأصول في النحو، تحقيق عبد الحسين الفتلي، جا. ص. • ب، مؤسسة الرسالة. شوقي ضيف. 971 1، المادرس النحوبين، ص. 1، القاهرة، دار المعارف. محمد الطنطوي. نشأة النحو وتاريخ أشهر النحاة الطبعة الثانية، ص. هV، القاهرة: دار المعارف. بدون السنة. سعيد الأفغاني، 991 19، من تاريخ النحو، بيروت، دار الفكر. عليّ بن يوسف القفطي، جـا9 ام. إنباه الرّواة على أنباه النّحاة، تحقيق محمّد أبو الفضل إبراهيم، دار الفكر العربيّ-القاهرة، ومؤسسة الكتب الثقافية-بيروت.

ابن جنّي ب ج هه، د. ت. الخصائص، تحقيق محمّد عليّ النّجار، دار الهدى للطباعة والنشر، بيروت-لبنان. عمرو بن بحر الجاحظ 1ه 19 م، البيان والتبيين، لقاهرة : مكتبة الخنانجي، بيروت : مكتبة الهلال، مدينة الكويت : المكتب العربي.

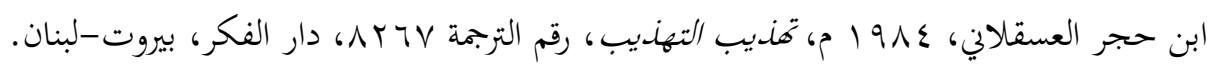
مصلح النجار وأفنان عبد الفتاح النجار، بدون السنة، نشأة النحو العربي، متقبب تاريخي. الزبيدى الاندلسى - أبى بكر محمد بن الحسن. عـ9 1،، طبقات النحويين و اللنحويين، دخائر العرب: دار المعارف. السيد عبدا لرمن، 971 ام، المدرسة البصرية النحوية نشنها و تطورها، قاهرة، دارا لمعارف. محمد الطتطاوى: نشأة النحو هو تاريخ أشهر النحاة، ص. 0V، دارا لمنار، 991 ام.

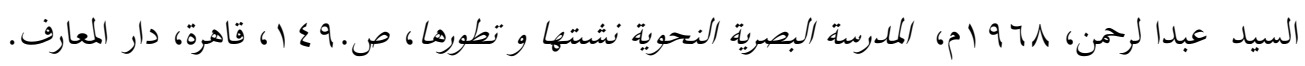
بروكلمان كارل ، 190 ام: تاريخ الآداب العبيّة، جr، نقله إلى العربية د. عبد الحليم النّجّار، ص. ب79 1، دار المعارف، القاهرة-

$$
\text { مصر، د. تم تمان. }
$$

مهدي المخزومي، 901 ام، مدرسة الكوفة و منهجها في دراسة اللغة و النحو، الطبعة الثانية، بغداد: شركة مكتبة.

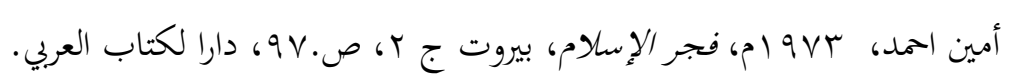

جلال الدين عبد الرحمن بن أبي بكر السيوطي، 9 197م، الاقتراح في علم أصول النحو: تحقيق: الدكتور أحمد محمد قاسم، الطبعة الأولى، مطبعة السعادة. القاهرة.

أبو البركات عبد الرحمن بن محمد الانباري، ا9V| I م، الإغراب في جدل الإعراب: قدم له وعني بتحقيقه : سعيد الأفغاني- الطبعة الثانية، دار الفكر - بيروت.

يجيى الشأوي المغربي الجزائري، •و9 19 م، إرتقاء السيادة في علم أصول النحو، تحقيق :الدكتور عبد الرزاق عبد الرحمن السعدي،

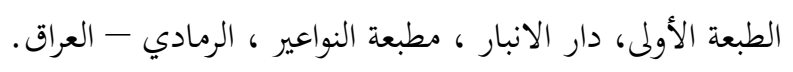

خديجة الحديثي، ع ا9 1 م، الشاهد وأصول النحو في كتاب سيبويه، ص. . ب، مطبوعات جامعة الكويت - الكويت. فاضل صالح السامرائي، و 19 م م، أبو البركات الأنباري ودراسته النحوية، الطبعة الأولى، دار الرسالة للطباعة - بغداد. خديجة الحديثي، ال191 م، موقف النحاة من الاحتجاج بالحلديث الشريف، الطبعة الأولى، ص. الى، دار الرشيد - بغداد. 


$$
\begin{aligned}
& \text { محمد غالب وراق، r . . r م، مباحث في مشكلات النحو العربي وسبل علاجها، السودان. } \\
& \text { محمد غالب وراق، } 1999 \text { م، الخصومة بين النحاة والشعراء أسبابها وصورها، جدة. }
\end{aligned}
$$

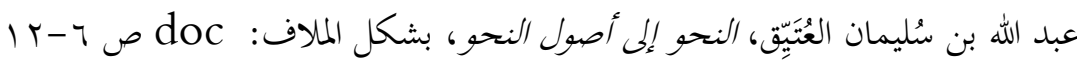

$$
\begin{aligned}
& \text { شرح العلامة ابن عقيل على ألفية جمال الدين محمل بن عبد الله بن مالك، ص. عـ-107 مكتبة الهداية سورابيا، د ت } \\
& \text { محمد عاشور الزهراني، أب م، أسباب نشأة علم النحو العربي، مجلة مركز الدراسات } \\
& \text { ب- المراجع الأجنبية والمواقع }
\end{aligned}
$$

Tamim Mulloh, 2015, al-Basith fi ushulin Nahwi wa Madarisihi, Lentera Kreasindo cet 3.

http://adwaa-jtc.blogspot.co.id/p/blog-page 1387.html

http://islamilimleri.com/Kulliyat/Lugat/2LugatveNahv/pg_176 0046.htm

www.marefa.org

www.alukah.net 
LiNGUA Vol. 16, No. 2, December 2021 • ISSN 1693-4725 • e-ISSN 2442-3823 